peutic action and the metabolic activities of the parasites. In the last chapter W. Balamuth and P. E. Thompson deal with the physiology and biochemistry of free-living and parasitic amœbæ, on one hand, and with amoebicidal drugs and their modus operandi against Entamoeba histolytica, on the other.

Each chapter is followed by a list of references, and at the end of the book there are author-and subjectindexes.

Like the first volume, the second is a symposium, the ten papers of which-written by recognized authorities-deal with diverse chemical activities in a variety of Protozoa, and contain important data of great value to protozoologists, physiologists and biochemists. There can be no doubt that the two volumes (and any which might follow) will provide the necessary material for the integration of the subject-matter in a publication where both the organisms and their chemical activities are arranged in systematic order.

C. A. HOARE

\section{WATER MITES OF THE WORLD}

Die Milben des Süsswassers und des Meeres Hydrachnellae et Halacaridae (Acari). Von Dr. Karl Viets. Zweiter und dritter Teil: Katalog und Nomenklator. Pp. iv +870 . (Jena: Veb. Gustav Fischer Verlag, 1956.) 94 D.M.

TN 1758 Linnaeus listed a single species of water mite in his "Systema Naturae". Some twenty years later O. F. Müller described, in an exemplary manner, forty-nine species from Denmark. Our knowledge of the group has continued to grow so that Dr. K. Viets now lists some 2,800 species of Hydrachnellae plus 270 or so species of the Halacaridae, and he visualizes further expansion of the list when the lesser-known parts of the world are examined. These are not always remote; for example, no water mites have yet been recorded from Luxemburg or Albania.

The first part of this work was published in 1955 and comprised a bibliography of water mites up to the end of 1953. The present volume forms the second and third parts, together with a supplementary bibliography to the middle of 1955 . The second part, occupying 700 pages, is a catalogue of the water mites of the world. This is not just a list of the generally accepted names. The authority, date and full synonymy are given for each taxonomic category, with cross-references to the bibliography. The location of descriptions of both sexes and of larval stages, if known, is given. The geographical distribution of each species is also given, in terms of continents with some details of countries, particularly in Europe.

The classification used in the catalogue is one largely pioneered by Dr. Viets and used in his monograph in the "Tierwelt Deutschlands" series. Dr. Viets, rather" naturally, prefers his own classification of the Rhombognathinae to that put forward by Newell. Time, and further work, will eventually settle this particular controversy. Meanwhile the classification adopted does not influence the effectiveness of the book.

The third part, or "Nomenklator", is a series of most useful indexes, giving page references to the catalogue. First there is a list of the higher taxonomic categories. Second, an alphabetical list of genera and subgenera, with the species and subspecies arranged alphabetically under each genus. Finally, there is an alphabetical list of specific names indicating the genera in which each name has been used. A feature of importance is that these lists include all the synonyms, so that it is possible to trace the names of species described or listed in any of the older works.

This book has been designed to work with, and it has a most impressive completeness. The specialist will use it as a constant reference book, and for the beginner it provides a key to the whole literature and synonymy of the group. The science of zoology would be greatly benefited if more groups of animals were covered by books of this authority and comprehensive. ness. It is regrettable that there is no modern list of the animals of the world. The present volume illustrates the difficulties and the labour involved in compiling such a list, but it also shows that the job could be done, if only systematists were encouraged by wider recognition of their work.

J. GREEN

\section{DAIRY CHEMISTRY}

\section{A Textbook of Dairy Chemistry}

By Dr. Edgar R. Ling. Third edition, revised. Vol. 1 : Theoretical. Pp. ix +227. 2ls. net. Vol. 2 : Practical. Pp. xi +140. 16s. net. (London: Chapman and Hall, Ltd., 1956.)

SINCE the second edition of this text-book appeared $S$ in 1944, much new knowledge has been gathered in the field of dairy chemistry, and the author has incorporated all that is essential in this revised edition. By using good judgment and sensible restraint, he has succeeded in bringing the text up to date without any undue increase in its length. The general lay-out remains unchanged. Vol. 1 deals largely with the constituents of milk, and the composition and properties of milk, cheese, butter and other dairy products; Vol. 2 with appropriate methods of testing. Formulæ are widely used to help the more advanced reader, but the language is sufficiently simple to assist those with but an elementary knowledge of chemistry. More than ever, therefore, the text-book-and particularly the first of the two slim, moderately priced, and attractively bound volumes-should find its place on the shelves not only of teachers and students, but also of advisers and those engaged in dairy research and technology. The latter will find much food for thought in such chapters as that on the composition of milk (Chapter 3, Vol. 1), which is particularly well balanced and includes a discussion of topical problems, such as the decline in the compositional quality of milk in Britain.

There is, however, still room for improvement. The present text contains an uncomfortable number of misprints. Some of the illustrations to Vol. 2 are poor, and the rather simple and incongruous Fig. $21 b$, depicting a stopper and a brush as used in connexion with the Gerber fat-test, could be eliminated with advantage. In a book designed primarily for educa. tional purposes, references should be given in a consistent and systematic manner. Authors' initials should be used throughout; how otherwise, for example, is the reader to know that the four references to Palmer in Vol. 1 refer to three different people? But these are blemishes that can easily be put right. All in all, the text-book is well on the way to becoming a 'classic'-and deservedly so.

R. Aschaffenburg 